\title{
HUBUNGAN ANTARA EFEK SAMPING KONTRASEPSI DMPA DENGAN KEJADIAN DROP OUT PADA PASANGAN USIA SUBUR (PUS) DI DESA MANDIREJO KECAMATAN MERAKURAK KABUPATEN TUBAN
}

\author{
Umu Qonitun*
}

*Dosen Program Studi D III Kebidanan STIKES Nahdlatul Ulama Tuban

\begin{abstract}
ABSTRAK
Drop out merupakan akseptor yang melepas kontrasepsi suntik DMPA sebelum jangka waktu yang ditentukan. Salah satu faktor yang memengaruhi kejadian drop out kontrasepsi Suntik DMPA pada pasangan usia subur yaitu efek samping yang terjadi pada akseptor. Tujuan penelitian ini adalah mengetahui hubungan antara efek samping kontrasepsi Suntik DMPA dengan kejadian drop out pada pasangan usia subur.Desain penelitian ini adalah analitik korelasional dengan pendekatan waktu Cross Sectional. Sampel berjumlah 73 responden yang dipilih menggunakan teknik simple random sampling. Instrument yang digunakan dalam penelitian ini adalah lembar kuesioner. Hasil penelitian ini menunjukan sebagian besar responden mengalami efek samping kontrasepsi Suntik DMPA sedang. Hasil uji statistik dengan Koefisien Kontingensi didapatkan nilai $\rho(0,007) \leq \alpha(0,05)$, maka H1 diterima yang berarti ada hubungan antara efek samping kontrasepsi Suntik DMPA dengan kejadian drop out pada pasangan usia subur.Dari hasil diatas dapat disimpulkan bahwa semakin berat efek samping yang dirasakan responden maka semakin tinggi kejadian drop out. Untuk itu diharapkan tenaga kesehatan memberikan informasi tentang efek samping kontrasepsi Suntik DMPA agar kejadian drop out pada akseptor kontrasepsi Suntik DMPA dapat dicegah.
\end{abstract}

\section{Kata kunci: Efek Samping Kontrasepsi Suntik DMPA, Drop Out, PUS}

\section{PENDAHULUAN}

Berdasarkan data dari Riskesdas (2014), jumlah peserta di Indonesia yang menggunakan kontrasepsi Suntik DMPA sebanyak 4,16\%. Data dari Dinas Kesehatan Kabupaten Tuban jumlah pengguna kontrasepsi Suntik DMPA tahun 2015 sebanyak 14.579 akseptor dan tahun 2016 sebanyak 11.281 akseptor. Data dari Puskesmas Kecamatan Merakurak pada bulan Januari-Oktober tahun 2015 Suntik DMPA sebanyak 662 akseptor dan tahun 2016 sebanyak 627 akseptor. Data dari Puskesmas Kecamatan Merakurak pada bulan Januari-Oktober tahun 2016 pengguna kontrasepsi Suntik DMPA terbanyak yaitu di Desa Mandirejo dengan jumlah 140 akseptor. Data tahun 20152016 menunjukkan jumlah pengguna kontrasepsi Suntik DMPA mengalami penurunan atau kurang dari target yang ditetapkan. Penurunan jumlah pengguna kontrasepsi Suntik DMPA karena terdapat beberapa akseptor yang mengalami drop out. Dari survei awal tanggal 22 Maret 2017 didapatkan 3 dari 10 akseptor mengatakan mengalami perubahan berat badan selama memakai kontrasepsi Suntik DMPA, 2 akseptor mengatakan mengalami nyeri kepala dan ketidaknyamanan yang dirasakan sehingga mengganggu aktivitas, dan 5 akseptor mengatakan mengalami gangguan haid selama memakai kontrasepsi Suntik DMPA.

Efek samping yang terjadi pada penggunaan kontrasepsi Suntik DMPA yaitu gangguan pola haid, pusing kepala, peningkatan atau penurunan berat badan, nyeri payudara, dan perasaan mual (Sulistyawati, 2014). Efek samping tersebut yang dapat mengakibatkan akseptor mengalami drop out kontrasepsi 
Suntik DMPA atau mencabut Suntik DMPAnya sebelum mencapai jangka waktu yang telah ditetapkan (BKKBN, 2013).

Alat kontrasepsi Suntik DMPA diminati oleh pasangan usia subur karena efektivitas tinggi, hal ini dapat dilihat dari data pengguna alat kontrasepsi Suntik DMPA. Keberhasilan alat kontrasepsi Suntik DMPA jika akseptor mampu bertahan dalam jangka waktu yang sudah ditetapkan. Fenomena di lapangan banyak dijumpai akseptor alat kontrasepsi Suntik DMPA telah mencabut Suntik DMPAnya sebelum jangka waktu yang sudah ditetapkan atau setelah dipakai kurang lebih dari satu tahun (BKKBN, 2013).

Waktu mulai menggunakan Suntik DMPA atau insersi dapat dilakukan setiap saat, dengan syarat diyakini tidak terjadi kehamilan (Sulistyawati, 2014). Kontrasepsi Suntik DMPA mempunyai daya guna yang tinggi, dan perlindungan kehamilan jangka panjang dalam waktu 35 tahun. Faktor-faktor yang mempengaruhi kejadian drop out kontrasepsi Suntik DMPA yaitu umur, paritas, tingkat pendidikan, tingkat pengetahuan, tingkat pendapatan, kualitas pelayanan kesehatan, dukungan suami, dan efek samping (BKKBN, 2007). Efek samping yang terjadi pada penggunaan kontrasepsi Suntik DMPA yaitu gangguan pola haid, pusing kepala, peningkatan atau penurunan berat badan, nyeri payudara, dan perasaan mual (Sulistyawati, 2014). Efek samping yang timbul dari kontrasepsi tersebut merupakan salah satu faktor pemicu akseptor untuk menghentikan kontrasepsi Suntik DMPA (BKKBN, 2013).

Oleh sebab itu diharapkan tenaga kesehatan untuk memberikan konseling dan penyuluhan tentang kontrasepsi Suntik DMPA. Akseptor melakukan kunjugan ulang agar akseptor lebih memahami dalam penggunaan dan tidak mengalami pemberhentian (drop out). Sehingga kejadian drop out akseptor kontrasepsi Suntik DMPA dapat dicegah (Saifuddin, 2010).

\section{METODE PENELITIAN}

Penelitian ini menggunakan desain penelitian Analitik Korelasional.Penelitian ini menggunakan pendekatan waktu Cross Sectional. Populasi dari penelitian ini adalah seluruh akseptor Suntik DMPA yang tercatat di Register Kohort Polindes Desa Mandirejo tahun 2016 dengan jumlah populasi 90 akseptor. Sampelyang digunakandalampenelitianiniadalahsebany ak73responden.sampling dalam penelitian ini menggunakan probability sampling yaitu simple random sampling. instrumenataualatukur yang digunakan adalah kuesioner. Penelitian ini dilaksanakan di Desa Mandirejo Kecamatan Merakurak Kabupaten Tuban.

\section{HASIL DAN PEMBAHASAN}

1. Hasil Penelitian

Tabel 1 Distribusi Frekuensi Responden Berdasarkan Umur di Desa Mandirejo Kecamatan Merakurak Kabupaten Tuban

\begin{tabular}{ccc}
\hline Umur & f & $\%$ \\
\hline $15-25$ tahun & 19 & $26,0 \%$ \\
$26-36$ tahun & 33 & $45,2 \%$ \\
$37-50$ tahun & 21 & $28,8 \%$ \\
\hline Jumlah & 73 & $100 \%$ \\
\hline
\end{tabular}

Tabel 2 Distribusi Frekuensi Responden Berdasarkan Pendidikan di Desa Mandirejo Kecamatan Merakurak Kabupaten Tuban

\begin{tabular}{ccc}
\hline Pendidikan & $\mathrm{f}$ & $\%$ \\
\hline Tidak Sekolah & 4 & $5,5 \%$ \\
SD/MI & 16 & $21,9 \%$ \\
SMP/MTS & 28 & $38,4 \%$ \\
SMA/MA & 21 & $28,8 \%$ \\
Perguruan Tinggi & 4 & $5,5 \%$ \\
\hline Jumlah & 73 & $100 \%$ \\
\hline
\end{tabular}

Tabel 3 Distribusi Frekuensi Responden Berdasarkan Pekerjaan di Desa Mandirejo Kecamatan Merakurak Kabupaten Tuban

\begin{tabular}{ccc}
\hline Pekerjaan & f & $\%$ \\
\hline Ibu Rumah Tangga & 34 & $46,6 \%$ \\
Tani & 0 & $0 \%$ \\
Wiraswasta & 27 & $37,0 \%$ \\
PNS & 2 & $2,7 \%$ \\
Lain-lain & 10 & $13,7 \%$ \\
\hline Jumlah & 73 & $100 \%$ \\
\hline
\end{tabular}


Tabel 4 Distribusi Responden Berdasarkan Efek Samping Kontrasepsi Suntik DMPA pada Pasangan Usia Subur (PUS) di Desa Mandirejo Kecamatan Merakurak Kabupaten Tuban

\begin{tabular}{ccc}
\hline Efek Samping & $\mathrm{f}$ & $\%$ \\
Kontrasepsi Suntik & & \\
DMPA & & \\
\hline Ringan & 24 & $32,9 \%$ \\
Sedang & 48 & $65,8 \%$ \\
Berat & 1 & $1,4 \%$ \\
\hline Jumlah & 73 & $100 \%$ \\
\hline
\end{tabular}

Tabel 5 Distribusi Responden Berdasarkan Kejadian Drop Outpada Pasangan Usia Subur (PUS) di Desa Mandirejo Kecamatan Merakurak Kabupaten Tuban

\begin{tabular}{ccc}
\hline Kejadian Drop Out & f & $\%$ \\
\hline Tidak Drop Out & 57 & $78,1 \%$ \\
Drop Out & 16 & $21,9 \%$ \\
\hline Jumlah & 73 & $100 \%$ \\
\hline
\end{tabular}

Tabel 6 Tabel Silang Hubungan Efek Samping Kontrasepsi Suntik DMPA dengan Kejadian Drop Out pada Pasangan Usia Subur (PUS) di Desa Mandirejo Kecamatan Merakurak Kabupaten Tuban

\begin{tabular}{cccc}
\hline Efek & \multicolumn{2}{c}{ Kejadian Drop } & Total \\
Samping & \multicolumn{2}{c}{ Out } & \\
\cline { 2 - 3 } Kontrase & $\begin{array}{c}\text { Tidak } \\
\text { psi }\end{array}$ & $\begin{array}{c}\text { Drop } \\
\text { Drop }\end{array}$ & Out \\
Suntik & Out & & \\
DMPA & & & \\
\hline Ringan & $42,1 \%$ & $0,0 \%$ & $100,0 \%$ \\
Sedang & $57,9 \%$ & $93,8 \%$ & $100,0 \%$ \\
Berat & $0,0 \%$ & $6,3 \%$ & $100,0 \%$ \\
\hline Jumlah & $78,1 \%$ & $21,9 \%$ & $100,0 \%$ \\
\hline
\end{tabular}

\section{Pembahasan}

Pembahasan ini akan diuraikan tentang hasil penelitian tentang Hubungan Efek Samping Kontrasepsi Suntik DMPA dengan Kejadian Drop Out pada Pasangan Usia Subur (PUS) di Desa Mandirejo Kecamatan Merakurak Kabupaten Tuban.

Berdasarkan tabel 1 diatas diperoleh data bahwa hampir setengahnya responden berumur 26 - 36 tahun yaitu 33 orang $(45,2 \%)$.
Berdasarkan tabel2 diatas diperoleh bahwa hampir setengahnya responden dengan pendidikan SMP/MTS yaitu 28 orang $(38,4 \%)$ dan sebagian kecil dengan pendidikan tidak sekolah dan perguruan tinggi yaitu $4(5,5 \%)$.

Berdasarkan tabel3 diatas diperoleh bahwa hampir setengahnya responden dengan pekerjaan ibu rumah tangga yaitu 34 orang $(46,6 \%)$ dan sebagian kecil dengan pekerjaan PNS yaitu $2(2,7 \%)$.

Berdasarkan tabel 4 diatas diperoleh data bahwa sebagian besar responden mengalami efek samping kontrasepsi Suntik DMPA sedang yaitu 48 orang $(65,8 \%)$ dan sebagian kecil mengalami efek samping kontrasepsi Suntik DMPA berat yaitu 1 orang $(1,4 \%)$.

Berdasarkan tabel 5 diatas diperoleh data bahwa hampir seluruhnya responden didapatkan kejadian tidak drop out sebanyak 57 orang $(78,1 \%)$ dan sebagian kecil responden didapatkan kejadian drop out sebanyak 16 orang $(21,9 \%)$.

Berdasarkan tabel 6 diatas diperoleh data bahwa responden mengalami efek samping kontrasepsi Suntik DMPA dengan kategori ringan tidak satupun mengalami kejadian drop out yaitu sebanyak $0(0,0 \%)$ responden. Responden yang mengalami efek samping kontrasepsi Suntik DMPA dengan kategori sedang sebagian besar mengalami kejadian tidak drop out yaitu sebanyak 33 (57,9\%) responden. Responden mengalami efek samping kontrasepsi Suntik DMPA berat sebagian kecil mengalami kejadian tidak drop out yaitu sebanyak 1 (6,3\%) responden.

Memilih dan menggunakan salah satu metode kontrasepsi dapat dilakukan setelah klien memperoleh informasi lengkap dan menjalani komunikasi oleh orang yang berwenang memberikannya. Adapun syarat-syarat yang harus dipenuhi oleh suatu metode kontrasepsi adalah aman pemakaiannya dan dapat dipercaya, efek samping yang merugikan tidak ada, lama kerjanya dapat diatur menurut keinginan, tidak mengganggu 
persetubuhan, cara penggunaanya sederhana, harganya murah dan dapat diterima oleh pasangan suami istri (BKKBN, 2005).

Menurut Sulistyawati (2014), efek samping yang terjadi pada penggunaan kontrasepsi Suntik DMPA yaitu gangguan haid, pusing kepala, peningkatan atau penurunan berat badan, nyeri payudara, dan perasaan mual.

Menurut peneliti sendiri efek samping yang sering terjadi pada akseptor KB karena belum tersedianya metode kontrasepsi yang sempurna atau tanpa efek samping.

Terjadinya efek samping bisa berbeda pada setiap individu tergantung dari daya tahan tubuh dan sistem hormon yang ada didalam tubuh masing-masing individu. Sebelum memberikan pelayanan kontrasepsi, tenaga kesehatan terlebih dahulu memberikan konseling tentang alat kontrasepsi yang akan digunakan oleh calon akseptor dan setiap kunjungan ulang mengkaji kembali tentang kelebihan dan kerugian dari setiap alat kontrasepsi yang digunakan oleh akseptor.

Menurut BKKBN (2007), ada beberapa faktor yang mempengaruhi kejadian drop out kontrasepsi Suntik DMPA yaitu umur, paritas, tingkat pendidikan, tingkat pengetahuan, tingkat pendapatan, kualitas pelayanan kesehatan, dukungan suami, dan efek samping.

Dari hasil penelitian kebanyakan akseptor Suntik DMPA tidak mengalami drop out. Hal tersebut dikarenakan akseptor mempunyai kecocokan dalam penggunaan kontrasepsi Suntik DMPA. Akseptor merasa aman atau tidak mengalami komplikasi berat jika menggunakan kontrasepsi Suntik DMPA, berdaya guna atau jika digunakan sesuai dengan aturan dapat mencegah kehamilan, dapat diterima bukan hanya oleh akseptor tetapi juga oleh lingkungan budaya dimasyarakat. Ada dua macam penerimaan terhadap kontrasepsi yaitu penerimaan awal (initial acceptability) dan penerimaan lanjut (continued acceptability).
Penerimaan awal tergantung pada bagaimana motivasi dan persuasi yang diberikan oleh petugas KB. Penerimaan lanjut dipengaruhi oleh banyak faktor seperti umur, motivasi, budaya, sosial ekonomi, agama, sikap yang ada pada akseptor $\mathrm{KB}$, dan faktor daerah atau lingkungan (Moeloek, 2005).

Menurut peneliti sendiri drop out merupakan akseptor yang keluar atau melepas Suntik DMPAnya sebelum jangka waktu yang telah ditetapkan. Beberapa faktor yang mempengaruhi kejadian drop out antara lain usia dan efek samping. Perilaku kesehatan juga memengaruhi individu untuk melakukan tindakan. Kadang-kadang meskipun orang tahu dan mampu untuk berperilaku sehat tetapi tidak melakukannya. Hal ini terwujud dalam perilaku individu untuk melakukan drop out alatkontrasepsi yang digunakan. Jika individu menyadari bahwa alat kontrasepsi itu penting untuk kesejahteraan keluarga, maka individu tersebut tidak akan melakukan drop out.

Hasil penelitian dapat dilihat bahwa ibu cenderung untuk drop out penggunaan alat kontrasepsi Suntik DMPA karena mengalami efek samping dari penggunaan alat kontrasepsi Suntik DMPA tersebut. Efek samping dari kontrasepsi Suntik DMPA yang sering ditemukan antara lain pola haid tidak teratur, amenorhea, masa menstruasi akan lebih lama, terjadi perdarahan bercak atau spotting bahkan mungkin menjadi anemia pada beberapa ibu, pusing kepala, peningkatan atau penurunan berat badan, nyeri payudara dan perasaan mual (BKKBN, 2003). Adapun efek samping yang umum terjadi dari kontrasepsi peningkatan atau penurunan berat badan, dan gangguan pola haid. Walaupun efek samping yang berat jarang ditemui, akan tetapi efek samping yang sangat menggangu kemungkinan dapat menyebabkan akseptor menghentikan penggunaannya (Sofian, 2013).

Hasil penelitian diperoleh nilaiApproximate Sig. $=0,002$ dimana 
$0,002<0,05$, maka $\mathrm{H}_{1}$ diterimaH $\mathrm{H}_{0}$ ditolak sehingga dapat disimpulkan bahwa ada hubungan efek samping kontrasepsi Suntik DMPA dengan kejadian drop out pada pasangan usia subur (PUS) di Desa Mandirejo Kecamatan Merakurak Kabupaten Tuban.

\section{KESIMPULAN}

Sebagian besar pasangan usia subur di Desa Mandirejo Kecamatan Merakurak Kabupaten Tuban mengalami efek samping kontrasepsi Suntik DMPA sedang. Sebagian kecil pasangan usia subur di Desa Mandirejo Kecamatan Merakurak Kabupaten Tuban mengalami kejadian drop out. Terdapat Hubungan Efek Samping Kontrasepsi Suntik DMPA dengan Kejadian Drop Out pada Pasangan Usia Subur (PUS) di Desa Mandirejo Kecamatan Merakurak Kabupaten Tuban.

\section{DAFTAR PUSTAKA}

BKKBN. 2003. Materi Konseling. Jakarta. diakses $16 \quad$ Oktober 2016. http://www.bkkbn.go.id/jabar/progra m_detail.php?prgid $=15$.

BKKBN. 2005. Ada Apa dengan Gender dalam Keluarga Berencana dan Kesehatan Reproduksi. Jakarta. diakses $29 \quad$ November 2016.http://www.BKKBN.go.id.

BKKBN. 2007. Banyaknya Pasangan Usia Subur (PUS) dan Akseptor Aktif Tahun 2007. Jawa Timur. diakses $09 \quad$ Desember 2016.http://www.BKKBN.go.id.

BKKBN. 2013. Laporan Program KB Nasional Tahun 2013. Diakses 23 Desember 2016.http://www.BKKBN.go.id.

Farid, A. Moeloek. 2005. Ilmu Bedah Kebidanan Kontrasepsi. Jakarta: FKUI. Diakses tanggal 10 Mei 2017. http://repository.usu.ac.id.

Saifuddin, A. B. 2010. Buku Panduan Praktis Pelayanan Kontrasepsi. Jakarta: YBPSP.

Sofian, A. 2013. Rustam mocthar sinopsis obstetri: Obstetri Operatif,
Obstetri Sosial Edisi 3. Jilid 2. Jakarta: Buku Kedokteran EGC.

Sulistyawati, Ari. 2014. Pelayanan

Keluarga Berencana. Jakarta:

Salemba Medika. 